\title{
What Explains the Lagged Investment Effect?*
}

\author{
Janice Eberly ${ }^{\dagger}$ Sergio Rebelo ${ }^{\ddagger}$ and Nicolas Vincent ${ }^{\S}$
}

\begin{abstract}
The best predictor of current investment at the firm level is lagged investment. This lagged-investment effect is empirically more important than the cash-flow and $Q$ effects combined. We show that the specification of investment adjustment costs proposed by Christiano, Eichenbaum and Evans (2005) predicts the presence of a lagged-investment effect and that a generalized version of their model is consistent with the behavior of firmlevel data from Compustat.
\end{abstract}

*We thank Nick Bloom for helpful discussions on the estimation algorithm used in this paper. ${ }^{\dagger}$ Northwestern University and NBER.

${ }^{\ddagger}$ Northwestern University, NBER and CEPR.

§HEC Montréal. 


\section{Introduction}

Lagged investment is a much better predictor of investment than Tobin's $Q$ and cash flow combined. While this fact has been recognized in empirical work on investment, it has mostly been viewed as an inconvenience. Hayahi's (1982) result that investment should depend only on Tobin's $Q$ placed $Q$ at the center of the empirical investment literature. The potential role of financial frictions or other deviations from Hayashi's framework motivated the subsequent work on the cash-flow effect found in the data. ${ }^{1}$ While much progress has been made in understanding the role of $Q$ and cash flow in investment regressions, an important question remains: what explains the lagged-investment effect?

In this paper we first document the importance and robustness of the laggedinvestment effect in firm-level Compustat data. We then use these data to estimate the investment adjustment-cost model proposed by Christiano, Eichenbaum, and Evans (2005) (henceforth CEE). This specification was initially designed to make the impulse response of investment to monetary policy shocks generated by DSGE models consistent with the impulse response estimated using vector auto-regressions. It has since become standard in the DSGE literature. ${ }^{2}$

We show analytically that the CEE model predicts the presence of a laggedinvestment effect in addition to cash flow and $Q$ effects. ${ }^{3}$ Moreover, regression coefficients obtained from our model-generated data are similar in magnitude to empirical estimates. We also find that a generalized version of CEE does surprisingly well at explaining the patterns of persistence, volatility, and comovement

\footnotetext{
${ }^{1}$ See Hubbard (1998) for a survey of the empirical literature on investment.

${ }^{2}$ Examples of papers that use this adjustment-cost specification include Fernández-Villaverde and Rubio-Ramírez (2004), Smets and Wouters (2007), Justiniano and Primiceri (2008), Del Negro and Schorfheide (2009), and Gertler and Kiyotaki (2010).

${ }^{3}$ Gilchrist and Himmelberg (1998) raise the possibility that the highly significant laggedinvestment effect in their data could be generated by a different adjustment-cost formulation.
} 
observed in firm-level data.

Our paper is organized as follows. In Section 2 we describe the data and document the presence of a lagged-investment effect. In Section 3 we show analytically that a linearized version of the CEE model predicts the presence of a lagged-investment effect. We then discuss a generalized version of the model that we use in our estimation. Section 4 presents our estimation results and discusses the model's implications for investment regressions. Section 5 concludes.

\section{The lagged-investment effect}

In this section we describe the data set and use it to document the importance of lagged investment as a predictor of current investment. We also summarize some key features of the data.

We use a balanced panel of Compustat firms with annual data for the period 1981-2003. We use a balanced panel because the time dimension of the data is important in identifying the dynamics of the model. The sample includes 776 firms and roughly 14,000 firm-year observations. We focus our analysis on the large firms in our dataset, defined as those in the top quartile of firms sorted by size of the capital stock in 1981. In the beginning of the sample, the top quartile of firms represents 30 percent of aggregate private non-residential investment and 40 percent of corporate non-residential investment. ${ }^{4}$ This focus on large firms coupled with the fact that the balanced panel selects for more stable firms means that we can reasonably abstract from any financing frictions which might be present for smaller firms. We use data for the four variables present in our model: investment in property, plant, and equipment, the physical capital stock, $Q$, and cash

\footnotetext{
${ }^{4}$ Despite our focus on the largest firms, there remains considerable size heterogeneity within that group: the time-series average of the capital stock ranges from 116 to 239,225 million dollars across the 194 firms.
} 
flow. We exclude from our sample firms that have made a major acquisition in order to definitively focus on investment as purchases of new property, plant, and equipment. We estimate the physical capital stock using the perpetual inventory method, using the book value of capital as the starting value for the capital stock and four-digit industry-specific estimates of the depreciation rate. $Q$ is calculated as the market value of equity plus the book value of debt, divided by the capital stock estimate. Cash flow is measured using the Compustat item for Income before extraordinary items + depreciation and amortization + minor adjustments. We describe the data and sample selection in more detail in Appendix 6.1.

\subsection{Key empirical features}

In Table 1 we report summary statistics for both the 1981-2003 period and for two sub-periods, 1981-1992 and 1993-2003. These estimates are similar to those reported in other studies that use Compustat data. Bootstrap standard errors are indicated in parenthesis. We report the median across firms of selected time-series moments. An alternative would have been to compute moments for the average across firms of the variables of interest. However, this procedure would eliminate the idiosyncratic variability associated with individual firms. Henceforth, to simplify the exposition we use $I / K$ and $C F / K$ to refer to the investment-capital ratio and the cash-flow-to-capital ratio, respectively.

The most striking features of the data are the important differences across sub-samples. In particular, the mean and standard deviation of $Q$ and $C F / K$ in the second sub-sample are significantly higher than in the earlier period. All variables exhibit positive skewness, and there is more skewness in the full sample than in each of the two sub-samples. Finally, $Q$ exhibits strong persistence, while the persistence in $I / K$ and $C F / K$ is more moderate. ${ }^{5}$

\footnotetext{
${ }^{5}$ We do not report serial correlation results for subsamples as they are imprecisely estimated
} 


\subsection{Investment regressions}

The three panels of Figure 1 provide scatter plots of pooled time-series-crosssection data that are useful to visualize the relation between $I / K$ and the three variables of interest: $Q, C F / K$ and lagged $I / K$.

We use $\log (Q)$ and $\log (C F / K)$ in our investment regression because, as discussed in Abel and Eberly (2002), this specification provides a better fit owing to skewness in the firm-level data. Similarly, the log specification makes our parameter estimates less sensitive to a small number of very high $Q$ values observed in the data. ${ }^{6}$

We now describe results from regressing $I / K$ on different combinations of three variables: $\log (Q), \log (C F / K)$, and lagged $I / K$.

In Panel A of Table 2 we report estimates from pooled, time-series-cross-section regressions. Comparing columns 1 and 2 we see that $Q$ and $C F / K$ individually have similar explanatory power. Regressing $I / K$ on either of these variables generates an $R^{2}$ of 30 percent. When both $Q$ and $C F / K$ are included in the regression (column 4 ), the goodness-of-fit rises slightly to 0.34 . We obtain a much higher $R^{2}(0.57)$ when we use lagged $I / K$ as the sole explanatory variable. When all three regressors are present, the coefficient on lagged $I / K$ remains large (0.6253) and very highly significant, while the coefficients on $Q$ and $C F / K$ are significant but small in magnitude (0.0126 and 0.017, respectively).

To investigate the robustness of the lagged-investment effect we run panel versions of these regressions with firm fixed effects. The results, reported in Panel B of Table 2, lead to similar conclusions. The explanatory power of lagged investment is much greater than that of $Q$ and $C F / K$ together $\left(R^{2}\right.$ of 0.57 versus 0.30$)$.

due to the low number of complete observations within a subsample for a number of firms.

${ }^{6}$ When we run linear regressions, the coefficient on $Q$ is small but significant, and the coefficient on $C F / K$ is larger and also statistically significant. These results accord with the investment regression results reported in the literature. 
When all three variables are included as regressors the coefficient on lagged $I / K$ is large (0.4462) and significant. The coefficient on $Q$ is small and significant, while the coefficient on $C F / K$ is marginally significant.

Since lagged investment is by definition correlated with the panel-level effects, we re-run the panel regressions using Arellano and Bond's (1991) consistent GMM estimator. The results are reported in Panel $\mathrm{C}$ of Table 2. The results obtained with this estimator are very similar to those reported in Panel B. In addition, the lagged-investment effect continues to be highly significant even when we include year dummies (column 3). Columns 4 and 5 of Panel $\mathrm{C}$ show that the laggedinvestment effect is present in both subsamples (1981-1992 and 1993-2003). We also find that including lags of both $Q$ and $C F / K$ has a negligible impact on the size and significance of the lagged-investment coefficient.

In sum, we find that lagged $I / K$ is a better predictor of current $I / K$ than $Q$ and $C F / K$, even when combined. The coefficient on lagged $I / K$ is roughly 0.40 . This lagged-investment effect is robust across specifications. $Q$ has a small but robust and significant effect on $I / K$. In contrast, the cash-flow effect is weak and not robust in our sample, becoming insignificant or negative in some of the regression specifications.

Next, we describe the CEE model and some of its properties.

\section{The CEE model}

The firm's problem is given by the following Bellman equation, where $y^{\prime}$ denotes next period's value of variable $y$ :

$$
V\left(K, I_{-1}, z\right)=\max _{I, K^{\prime}} z K-I+\beta \int V\left(K^{\prime}, I, z^{\prime}\right) F\left(d z^{\prime}, z\right),
$$

subject to:

$$
K^{\prime}=I-I \phi\left(I / I_{-1}\right)+(1-\delta) K .
$$


The firm's output is given by $z K$, where $K$ denotes the stock of capital and $z$ is a stochastic variable governed by the distribution $F(\cdot)$. This variable represents a shock to productivity or to the price of the firm's output. We can interpret the production function as requiring a single productive factor, capital. Alternatively, we can think of output as being produced with capital, labor, and other variable factors, with labor and variable factors being costlessly adjustable. In this case $z K$ represents output net of labor and other variable costs. Under this interpretation, which we adopt throughout the paper, the variable $z$ can also incorporate shocks to the real wage or to the price of other variable factors.

Investment, denoted by $I$, is subject to adjustment costs according to the CEE specification which is given by equation (3.2), where $\phi^{\prime \prime}()>.0 .^{7}$

It is convenient to assume that in a deterministic steady state with constant $z$ there are no adjustment costs. This property requires that:

$$
\phi(1)=\phi^{\prime}(1)=0 .
$$

The function $V\left(K, I_{-1}, z\right)$ represents the value of a firm with capital stock $K$, lagged investment, $I_{-1}$, and total factor productivity, $z$. Lagged investment is a state variable for the firm because it enters the adjustment cost specification given by equation (3.2). We denote the discount factor by $\beta$. Capital depreciates at rate $\delta$.

The optimal solution to the firms problem is characterized by the first-order conditions for $K^{\prime}$ and $I$ :

$$
\begin{aligned}
\lambda & =\beta \int V_{1}\left(K^{\prime}, I, z^{\prime}\right) F\left(d z^{\prime}, z\right), \\
1 & =\lambda-\lambda \phi\left(I / I_{-1}\right)-\lambda\left(I / I_{-1}\right) \phi^{\prime}\left(I / I_{-1}\right)+\beta \int V_{2}\left(K^{\prime}, I, z^{\prime}\right) F\left(d z^{\prime}, z\right),
\end{aligned}
$$

\footnotetext{
${ }^{7}$ Matsuyama (1984) and Lucca (2007) provide microfoundations for this adjustment cost formulation.
} 
and two envelope conditions:

$$
\begin{aligned}
& V_{1}\left(K, I_{-1}, z\right)=z+\lambda(1-\delta) \\
& V_{2}\left(K, I_{-1}, z\right)=\lambda \phi\left(I / I_{-1}\right)\left(I / I_{-1}\right)^{-2} .
\end{aligned}
$$

The variable $\lambda$ denotes the Lagrange multiplier associated with equation (3.2).

To study the properties of this problem we linearize the first-order conditions around a deterministic steady state. Equations (3.5) and (3.7), together with the requirement of no adjustment costs in the steady state (equation (3.3)), imply that the steady state value of $\lambda$ is equal to one. Equations (3.2) and (3.3) imply that the steady state level of investment is: $I=\delta K$.

We assume that the steady state value of $z$ satisfies the following equation:

$$
1 / \beta-1=z-\delta
$$

The left-hand side of this equation is the real interest rate faced by the firm. The right-hand side is the marginal product of capital net of depreciation.

Equation (3.1) and condition (3.8) imply that the steady state value of the firm is given by:

$$
V=K / \beta
$$

Tobin's (average) $q$ is defined as: ${ }^{8}$

$$
Q=V / K=1 / \beta
$$

Linearizing equation (3.2) around the steady state we obtain:

$$
\hat{K}_{t+1}=\delta \hat{I}_{t}+(1-\delta) \hat{K}_{t}
$$

${ }^{8}$ The steady-state value of $Q$ is different from one because this version of Tobin's $Q$ is based on the value of the firm in the beginning of the period. The value of $Q$ computed using the end of period value of the firm (after cash flow has been received and investment expenditures have been incurred) is equal to one. This effect of timing on the value of $Q$ is common in discrete time models. 
where

$$
\chi=\phi^{\prime \prime}(1)>0 .
$$

Combining equations (3.4)-(3.7) and linearizing the resulting conditions we obtain:

$$
\begin{gathered}
\hat{\lambda}_{t} / \beta=E_{t}\left[z \hat{z}_{t+1}+(1-\delta) \hat{\lambda}_{t+1}\right], \\
0=\hat{\lambda}_{t}-\chi\left(\hat{I}_{t}-\hat{I}_{t-1}\right)+\beta \chi\left(\hat{I}_{t+1}-\hat{I}_{t}\right) .
\end{gathered}
$$

To study the properties of the investment regressions implied by the linearized version of the model we assume that $\hat{z}_{t}$ follows an $\operatorname{AR}(1)$ process with first-order serial correlation $\rho$. The resulting solution to the firm's problem takes the form:

$$
\hat{I}_{t}=\pi_{i i} \hat{I}_{t-1}+\pi_{i z} \hat{z}_{t}+\pi_{i k} \hat{K}_{t}
$$

Solving for coefficients $\pi_{i i}, \pi_{i A}$, and $\pi_{i k}$ using the method of undetermined coefficients we obtain:

$$
\hat{I}_{t}=\hat{I}_{t-1}+\frac{\beta \rho}{1-\beta \rho} \frac{z / \chi}{1-(1-\delta) \beta \rho} \hat{z}_{t}
$$

The properties of this solution are as follows. The higher the degree of adjustment costs, $\chi$, the smaller the response of investment to a given shock. The higher the degree of shock persistence, $\rho$, the stronger the response of investment to shocks. When shocks are i.i.d. $(\rho=0)$ investment is constant over time.

It is useful to use this linearized solution to compute Tobin's $Q$. Combining the equation for the value of the firm and the linearized laws of motion for investment and capital yields:

$$
\hat{V}_{t}=\frac{z}{1 / \beta-\rho} \hat{z}_{t}+\hat{K}_{t} .
$$

In general $\hat{V}_{t}$ should be a function of the state variables $\hat{K}_{t}, \hat{I}_{t-1}$ and the shock, $\hat{z}_{t}$. The fact that $\hat{V}_{t}$ does not depend on $\hat{I}_{t}$ results from adjustment costs being 
zero in steady state. Equation (3.14) implies that $\hat{Q}_{t}$ is given by:

$$
\hat{Q}_{t}=\hat{V}_{t}-\hat{K}_{t}=\frac{\beta z}{1-\beta \rho} \hat{z}_{t}
$$

We can now use equation (3.13) to study the model's implications for the form of the investment regression equation. We denote the investment-capital ratio by $i_{t}=I_{t} / K_{t}$.

Using the policy function for investment and the linearized law of motion for the capital stock we obtain the following expression for $\hat{\imath}_{t}$ :

$$
\hat{\imath}_{t}=(1-\delta) \hat{\imath}_{t-1}+\frac{\beta \rho}{1-\beta \rho} \frac{z / \chi}{1-(1-\delta) \beta \rho} \hat{z}_{t} .
$$

The investment-capital ratio is a linear function of its own lag and the shock, $\hat{z}_{t}$. Since cash-flow/capital in deviation from its steady state value is equal to $\hat{z}_{t}$ $\left(\hat{C}_{t}-\hat{K}_{t}=\hat{z}_{t}\right)$, it enters significantly in a regression of $\hat{\imath}_{t}$ on $\hat{\imath}_{t-1}$. Equations (3.15) and (3.16) imply that if $\hat{Q}$ is included in the regression instead of cash-flow, we obtain a positive regression coefficient given by $z /\{\chi[1-(1-\delta) \beta \rho]\}$.

In sum, this model predicts the presence of a lagged-investment effect as well as a role for cash-flow or $Q$. A simple modification of the model allowing both a cashflow and $Q$ effect in addition to the lagged investment effect involves assuming that the production function has decreasing returns to scale. We pursue this modification below.

Generalizing the model Before estimating the model we generalize this basic specification to make it more compatible with the data along four dimensions. First, we allow for "flexible capital" which can be installed within the period without adjustment costs. Second, we introduce the possibility of decreasing returns to scale (DRS) in production. Third, we incorporate exogenous technical progress, so that in the absence of shocks capital, investment and cash flow grow at a constant trend. Fourth, we introduce a fixed cost in production. 
All four features are useful in improving compatibility between model and data. Flexible capital allows the model to better fit the persistence properties of investment. As discussed above, DRS allows the model to generate both a $Q$ and a cash-flow effect, in addition to the lagged-investment effect. Technical progress introduces a time trend similar to the one present in the data. Finally, the fixed cost scales profitability and allows the model to match the average level of $Q$ in the data.

The firm's problem in this generalized model is given by:

$$
\begin{aligned}
V\left(K, H, I_{-1}, X, z\right)= & \max _{I, I^{b}, K^{\prime}} z K^{\alpha}\left(H^{\prime}\right)^{\omega} X^{1-\alpha-\omega}-\theta X-I+ \\
& \beta \int V\left(K^{\prime}, H^{\prime}, I, z^{\prime}\right) F\left(d z^{\prime}, z\right),
\end{aligned}
$$

subject to:

$$
\begin{aligned}
& K^{\prime}=I-I \phi\left(I / I_{-1}\right)+(1-\delta) K, \\
& H^{\prime}=I^{h}+(1-\delta) H .
\end{aligned}
$$

The variable $X$ denotes the level of exogenous technological progress. This variable grows at a constant rate $\gamma>1, X^{\prime}=\gamma X$. The parameter $\theta$ controls the fixed operating cost paid in every period. This cost, $\theta X$, is fixed with respect to the investment decision, but grows at rate $X$, so that it does not become irrelevant as the firm gains in size.

The variables $H$ and $I^{h}$ denote the stock of flexible capital and the investment in flexible capital, respectively. The production function depends on $H^{\prime}$ so the stock of flexible capital that is relevant for production is chosen after the shock is realized. Both stocks of capital depreciate at rate $\delta$.

We assume that $\alpha+\omega<1$. We can interpret this property as reflecting the presence of decreasing returns to scale (DRS) in production. Alternatively, we can think of $\alpha+\omega<1$ as resulting from a setting in which the production function 
exhibits constant-returns to scale but the firm has monopoly power and faces a constant-elasticity demand function.

We assume that the adjustment cost function, $\phi$, takes a quadratic form:

$$
\phi\left(I / I_{-1}\right)=1-\xi\left(I / I_{-1}-\gamma\right)^{2} .
$$

This formulation has the property that adjustment costs are zero when the firm grows at its steady state growth rate, $\gamma$. The parameter $\xi$ controls the size of the adjustment cost.

We define cash-flow $\left(C F_{t}\right)$ as:

$$
C F_{t}=z K^{\alpha}\left(H^{\prime}\right)^{\omega} X^{1-\alpha-\omega}-\theta X,
$$

which is revenue net of fixed operating costs.

Shock process We assume that the shock $z$ follows a first-order Markov chain with support:

$$
z \in\left\{\mu^{L}-\sigma^{L}, \mu^{L}, \mu^{L}+\sigma^{L}, \mu^{H}-\sigma^{H}, \mu^{H}, \mu^{H}+\sigma^{H}\right\},
$$

where:

$$
\begin{aligned}
& \mu^{L}=1-\sigma^{*}, \\
& \mu^{H}=1+\sigma^{*} .
\end{aligned}
$$

The transition matrix is given by:

$$
\pi=\left[\begin{array}{cccccc}
p_{11} & p_{12} & p_{13} & 0 & 0 & 0 \\
p_{21} & p_{22} & p_{23} & p_{24} & 0 & 0 \\
p_{31} & p_{32} & p_{33} & p_{34} & 0 & 0 \\
0 & 0 & p_{43} & p_{44} & p_{45} & p_{46} \\
& & p_{53} & p_{54} & p_{55} & p_{56} \\
& & & p_{64} & p_{65} & p_{66}
\end{array}\right]
$$


where $\pi_{i j}=\operatorname{Pr}\left(z_{t+1}=z_{j} \mid z_{t}=z_{i}\right)$.

This specification allows the variable $z_{t}$ to alternate between two regimes, the low regime $\left(\mu^{L}-\sigma^{L}, \mu^{L}, \mu^{L}+\sigma^{L}\right)$ and the high regime $\left(\mu^{H}-\sigma^{H}, \mu^{H}, \mu^{H}+\sigma^{H}\right)$. The variable $\sigma^{*}$ governs the distance between the means of the two regimes. To reduce the number of parameters to be estimated we make some symmetry assumptions: $p_{11}=p_{66}, p_{22}=p_{55}, p_{33}=p_{44}, p_{34}=p_{43}$, and $p_{24}=p_{53}$.

A single regime process is a particular case of this specification, so the estimation algorithm can choose a single regime if it provides a better fit to the data. We find that the "regime-switching" specification allows the model to be consistent with three important features of the data. First, data moments are different in our two subsamples (1981-1992 and 1993-2003). Second, all variables exhibit skewness which arises naturally with regime switching. Third, regime-switching can generate the imperfect correlation between cash flow and $Q$ that we observe in the data. ${ }^{9}$

\section{Estimating the model}

We solve the model numerically using the procedure described in Appendix 6.3. Our solution method does not yield an analytical representation for the population moments implied by the model. For this reason, we estimate the model using the simulated method of moments proposed by Lee and Ingram (1991). We first use our data to estimate the vector of moments $\Psi_{D}$. We focus on the moments that are most directly related to the parameters of the model. The moment vector that we use includes the mean and standard deviation of $C F / K$ in both time periods as well as its serial correlation (to identify the shock process), the standard deviation and skewness of $I / K$ (to identify adjustment costs), the mean of $Q$ in both time periods (to identify the fixed cost), and the serial correlation of $Q$. These moments

\footnotetext{
${ }^{9}$ The median, across firms, of the correlation between $Q$ and $C F / K$ is 0.58 .
} 
are reported in bold in Table 1.

We find the parameter vector $\hat{\Phi}$ that minimizes the distance between the empirical and simulated moments, $\Psi(\hat{\Phi})$,

$$
L(\hat{\Phi})=\min \left[\Psi(\Phi)-\Psi_{D}\right]^{\prime} W\left[\Psi(\Phi)-\Psi_{D}\right]
$$

The weighting matrix $W$ is computed using a block-bootstrap method on our panel dataset (see Appendix 6.4 for a description). This estimation method gives a larger weight to moments that are more precisely estimated in the data

We solve the minimization problem (4.1) using an annealing algorithm to reduce the risk of convergence to a local minimum. ${ }^{10}$ Finally, the standard errors of the estimated parameters are computed as

$$
\hat{\Omega}=\frac{\left(\Gamma^{\prime} W \Gamma\right)^{-1}}{n},
$$

where $\Gamma$ is the matrix of derivatives,

$$
\Gamma=\frac{\partial \Psi(\hat{\Phi})}{\partial \hat{\Phi}},
$$

which we compute numerically. The estimation method is discussed in more details in Appendix 6.4.

\subsection{Parameter and moment estimates}

We choose the exogenous rate of technical progress to be $\gamma=1.03$. This growth rate is equal to the real annual growth rate of corporate net cash flows from January 1981 to January 2004. We fix the sum $\alpha+\omega$ because we cannot separately identify $\alpha+\omega$ and $\xi$ using the moments of the data that we consider. Both parameters control curvature, so when $\alpha+\omega$ changes, the value of $\xi$ can be

\footnotetext{
${ }^{10} \mathrm{We}$ also tested the robustness of our results by experimenting with various starting values of the model parameters.
} 
adjusted to restore the fit of the model. Hence, we set $\alpha+\omega=0.8$, consistent with the estimate of the average degree of returns to scale across industries by Burnside (1996).

We report our parameter estimates and standard errors in Table 3. Our estimate of the adjustment cost parameter, $\xi$, is 0.929 (with a standard error of 0.0113). This value is close to that obtained by CEE using macro data. ${ }^{11}$

Our estimate of the fixed operating cost parameter, $\theta$, is 86.22 (with a standard error of 1.2539) which corresponds to 18.8 percent of average cash flow. The weight on flexible capital, $\omega$, is relatively small ( 0.07 with a standard error of 0.0005$)$. It implies that flexible capital represents on average 8.7 percent of total capital, and that investment in flexible capital is on average 5.1 percent of total investment. ${ }^{12}$

We normalize the average shock $z$ to one. We estimate the spread between shocks to be 0.0915 . As we discuss below, these values allow the model to match the mean and standard deviation of the cash-flow-capital ratio in the data.

The high regime has a higher average productivity, but also a higher standard deviation. It is interesting to note that the support of the two regimes overlap. In fact, the low shock in the high regime is lower than the low shock in the low regime. This configuration of shocks makes the model consistent with the imperfect correlation between investment, $Q$ and cash-flow. When the shock is in the low regime cash-flow is low and investment opportunities are poor, so investment and $Q$ are low. In contrast, when the shock is in the high regime cash flow is low but investment opportunities are good, so investment and $Q$ are high. These estimates emphasize the importance of a structure in which $Q$ and cash-flow are not informationally redundant.

\footnotetext{
${ }^{11} \mathrm{CEE}$ estimate $\phi^{\prime \prime}(1)=2.48$, where $\phi^{\prime \prime}(1)$ is the second derivative of the adjustment cost function evaluated at the steady state. In our case the adjustment cost function is quadratic, so $\xi=\phi^{\prime \prime}(1) / 2$ which yields $\phi^{\prime \prime}(1)=1.86$.

${ }^{12}$ For reference, software investment alone accounted for $7 \%$ of total investment expenditure in the National Income and Product Accounts (NIPA) in 1993, the middle point of our sample.
} 
The estimated Markov chain described in Table 4 exhibits strong persistence: the parameter $\rho$ is 0.5595 (recall that our data has annual frequency). We also estimate the probabilities of switching regime from either the middle state or from the state closest to the alternative regime (e.g., transiting from the highest low state to the high regime, or from the lowest high state to the low regime). These probabilities are 3.23 percent and 7.44 percent, respectively. These estimates imply that the (unconditional) probability of a regime switch is 3.7 percent per year, so there is on average a regime switch every 27 years.

Table 1 reports summary statistics for variables simulated from the model. The moments in bold are included in the $\Psi_{D}$ vector, so our estimation algorithm seeks to make these moments as close as possible to those estimated from Compustat data. The remaining moments are not "targeted" by the algorithm. The algorithm matches all of the targeted moments closely.

One moment which the model cannot match is the standard deviation of $Q .{ }^{13}$ It is much lower in the model (0.309) than in the data (0.625). Erikson and Whited (2000) make a compelling case for the hypothesis that there is substantial measurement error in $Q$. Their estimates imply that we should increase the standard deviation of $Q$ generated by the model by 47 percent to incorporate the effect of measurement error that is present in the data. Using this adjustment we obtain a standard deviation of $Q$ equal to: $0.309 \times 1.47=0.454$. This value is still lower than the volatility of $Q$ in our sample but very close to the lower bound of the 95 percent confidence interval for the standard deviation of $Q$ : $0.625-(2 \times 0.083)=0.459$.

The finding that the model generates a volatility of $Q$ that is lower than that of the data is common in adjustment-cost models. A potential additional source of volatility are differences between the intrinsic value and the market value of

\footnotetext{
${ }^{13}$ Results are little changed if we include this moment in $\Psi_{D}$.
} 
equity (Shiller $(1989,2000)$ ). There is some evidence consistent with this view: measures of $Q$ that do not rely on the market value of equity tend to be better predictors of investment than conventional measures of $Q$. Examples of these alternative $Q$ measures are estimates based on cash-flow forecasts (Gilchrist and Himmelberg (1995)), analyst forecasts of earnings growth (Cumins, Hassett, and Oliner (2006)), and bond prices (Philippon (2009)).

Finally, in order to evaluate the role played by flexible capital we re-estimate the model setting $\omega$ to zero. We obtain very similar parameter estimates. The adjustment cost parameter is 0.98 instead of 0.93 in the model with flexible capital. The fit to the data of the two versions of the model is similar with one exception: the serial correlation of investment is too high in the model without flexible capital (0.94). Flexible capital, while a small share of investment in the model, is important to match the persistence of total investment even if it plays little role for other moments.

\subsection{Simulated regression results}

We now regress investment on its determinants using simulated data. We report our results in Table 2, Panel D. Regressing $I / K$ on $\ln (Q)$ yields an $R^{2}$ of only 0.27 and a coefficient of 0.105 on $\ln (Q)$. Regressing $I / K$ on $\ln (C F / K)$ yields an $R^{2}$ of 0.17 and a cash-flow coefficient of 0.047 . Including both $\ln (Q)$ and $\ln (C F / K)$ in the regression raises the $R^{2}$ to 0.3 . Regressing $I / K$ only on lagged $I / K$ yields an $R^{2}$ of 0.32 and a lagged-investment coefficient of 0.565 . Finally, regressing $I / K$ on lagged $I / K, \ln (Q)$ and $\ln (C F / K)$ we obtain and $R^{2}$ of 0.45 .

Comparing the model's result to the regression results from the data in Panel C, column 2 (in bold), the lagged-investment effect is very similar (0.42 in both cases). The $Q$ effect is also similar in the model and in the data (0.053 versus 0.04). The cash-flow effect is negligible in the data, while it is weak but significant 
in the model (0.024).

\section{Conclusions}

We find that the investment adjustment cost specification proposed by Christiano, Eichenbaum and Evans (2005) provides a good fit to firm-level data. It can also explain the strong and robust lagged investment effect found empirically.

Since the CEE specification penalizes changes in the level of investment, the reader might find this result surprising. After all, aren't periods of zero investment followed by investment spikes and irreversibilities key features of micro data? It depends on the level of aggregation that we consider. Irreversibilities and jumps are important in plant data. But they are not important for the large Compustat firms included in our sample. Doms and Dunne (1998) show that aggregating data for smaller firms or for individual plants tends to smooth out non-convexities in investment. An interesting question for future research is to investigate how the right model of investment varies with the level of aggregation and whether the CEE specification can emerge from aggregating adjustment cost models that are consistent with plant data. 


\section{References}

[1] Abel, Andrew, and Janice Eberly, "Investment and $Q$ With Fixed Costs: An Empirical Analysis," working paper, 2002.

[2] Burnside, Craig "Production Function Regression, Returns to Scale and Externalities," Journal of Monetary Economics, 37: 177-201, 1996.

[3] Christiano, Lawrence, Martin Eichenbaum, and Charles Evans "Nominal Rigidities and the Dynamic Effects of a Shock to Monetary Policy," Journal of Political Economy, 113: 1-45, 2005.

[4] Cummins, Jason G., Hassett, Kevin A. and Stephen D. Oliner "Investment Behavior, Observable Expectations, and Internal Funds," American Economic Review, 96: 796-810, 2006.

[5] Del Negro, Marco and Frank Schorfheide "Monetary Policy Analysis with Potentially Misspecified Models," American Economic Review, 99: 1415-50, 2009 .

[6] Doms, Mark and Timothy Dunne, "Capital Adjustment Patterns in Manufacturing Plants," Review of Economic Dynamics, 1: 409-429, 1998.

[7] Erickson, T. and Toni Whited, "Measurement Error and the Relationship between Investment and ' $q$ '," The Journal of Political Economy, 108: 1027$1057,2000$.

[8] Fernández-Villaverde, Jesús and Juan Francisco Rubio-Ramírez "Comparing Dynamic Equilibrium Models to Data: a Bayesian Approach," Journal of Econometrics, 123: 153-187, 2004. 
[9] Gertler, Mark and Nobuhiro Kiyotaki "Financial Intermediation and Credit Policy in Business Cycle Analysis ," mimeo, New York University, 2010.

[10] Gilchrist, Simon and Charles Himmelberg, "Evidence on the Role of Cash Flow for Investment," Journal of Monetary Economics 36: 541-572, 1995.

[11] Gilchrist, Simon and Charles Himmelberg "Investment: Fundamentals and Finance," NBER Macroeconomics Annual, 13: 223-262, 1998.

[12] Hayashi, Fumio, "Tobin's Marginal $Q$ and Average $Q$ : A Neoclassical Interpretation," Econometrica, 50: 215-224, 1982.

[13] Hubbard, R. Glenn "Capital-Market Imperfections and Investment," Journal of Economic Literature, 36: 193-225, 1998.

[14] Jorgenson, Dale and Ralph Landau, Tax Reform and the Cost of Capital: an International Comparison, Washington, DC: Brookings Institution, 1993.

[15] Justiniano, Alejandro and Giorgio Primiceri "The Time Varying Volatility of Macroeconomic Fluctuations," The American Economic Review, 98: 604-641, 2008.

[16] King, Mervyn and Don Fullerton, The Taxation of Income from Capital: a Comparative Study of the United States, the United Kingdom, Sweden, and West Germany; University of Chicago Press, Chicago, 1984.

[17] Lkhagvasuren, Damba "Big Locational Differences in Unemployment Despite High Labor Mobility," mimeo, Northwestern University, 2006.

[18] Lee, B. and Ingram B. "Simulation estimation of time series models", Journal of Econometrics, 47: 197-205, 1991. 
[19] Lucca, David. "Resuscitating Time-to-Build," mimeo, Federal Reserve Bank of New York, 2007.

[20] Matsuyama, Kiminori "A Learning Effect Model of Investment: An Alternative Interpretation of Tobin's q," mimeo, Northwestern University, 1984.

[21] Philippon, Thomas "The Bond Market's Q," Quarterly Journal of Economics, 124: 1011-1056, 2009.

[22] Salinger, Michael A. and Lawrence Summers, "Tax Reform and Corporate Investment: A Microeconomic Simulation Study," in Martin S. Feldstein, editor, Behavioral Simulation Methods in Tax Policy Analysis, University of Chicago Press, 247-287, 1983.

[23] Smets, Frank and Rafael Wouters "Shocks and frictions in U.S. business cycles: A Bayesian DSGE approach," American Economic Review, 97:3, 586606, 2007.

[24] Shiller, Robert J. Market volatility, Cambridge, MA: MIT Press, 1989.

[25] Shiller, Robert J. Irrational exuberance, Princeton: Princeton University Press, 2000. 


\section{Appendix}

\subsection{Data Sources and Calculations}

Annual data items from the dataset cstsann in the CRSP/Compustat Merged database, 1981-2003, are first listed, followed by the calculations underlying the constructed variables. Sources for non-Compustat items are given in parentheses.

- $I$ : expenditures on property, plant, and equipment, data 30

- CashFlow: income before extraordinary items + depreciation and amortization + minor adjustments, calculated as follows (from the Compustat manual):

Income Before Extraordinary Items, 123

+ Depreciation and Amortization, 125

+ Extraordinary Items and Discontinued Operations, 124

+ Deferred Taxes, 126

+ Equity in Net Loss (Earnings), 106

+ Sale of Property, Plant, and Equipment and Sale of Investments - Loss(Gain), 213

+ Funds from Operations - Other, 217

+ Accounts Receivable - Decrease (Increase), 302

+ Inventory - Decrease (Increase), 303

+ Accounts Payable and Accrued Liabilities - Increase (Decrease), 304

+ Income Taxes - Accrued - Increase (Decrease), 305

+ Assets and Liabilities - Other (Net Change), 307

$=$ Operating Activities - Net Cash Flow, 308

- inventories: total inventories (end of period), data 3 
- debt: long-term debt (end of period), data 9

- $P P E$, book value of capital: property, plant, and equipment,

- data 182: PPE - Beginning Balance - check if it is still reported after 1997 ;

- data 187: PPE - Ending Balance (Schedule V);

- data 184: PPE - Retirements (Schedule V) - not reported after 1997;

- data 185: PPE - Other Changes (Schedule V) - not reported after 1997.

- $P_{k}$, price of capital: implicit price deflator for nonresidential investment, Economic Report of the President, Table B-3, various years.

- $u$, investment tax credit: obtained by year for 51 asset classes from Dale Jorgenson. These data are aggregated to the two-digit industry level using the BEA historical cost capital flow matrix (asset by industry by year). Specifically, the weight of asset type $\mathrm{n}$ in industry $\mathrm{j}$ in year $\mathrm{t}$ is calculated as $w_{n, j, t} \equiv I_{n, j, t} / \sum_{n} I_{n, j, t}$. The investment tax credit applied to industry j in year t, $u_{j, t}$, is then constructed as the weighted sum $u_{j, t}=\sum_{n} w_{j, n, t} u_{j, n, t}$.

- $z$, value of depreciation allowances: obtained by year for 51 asset classes from Dale Jorgenson. These data are aggregated to the two-digit industry level using the BEA historical cost capital flow matrix (asset by industry by year). Specifically, the weight of asset type $\mathrm{n}$ in industry $\mathrm{j}$ in year $\mathrm{t}$ is calculated as $w_{n, j, t} \equiv I_{n, j, t} / \sum_{n} I_{n, j, t}$. The value of depreciation allowances in industry $\mathrm{j}$ in year $\mathrm{t}, z_{j, t}$, is then constructed as the weighted sum $z_{j, t}=\sum_{n} w_{j, n, t} z_{j, n, t}$.

- $\tau$, corporate tax rate: obtained from King and Fullerton (1984), table 6.4, and Fullerton and Karayannis (in Jorgenson and Landau (1993)), p. 343, updated to 2003 by Dale Jorgenson. 
- market value of equity: closing stock price times number of common shares outstanding (end of period) plus redemption value of preferred stock (end of period $)=\operatorname{prc} *$ shrout $/ 1000+$ data56, where,

- prc: closing stock price from msf file (monthly stock - securities);

- shrout: Common shares outstanding from msf file (monthly stock securities);

- data 56: Preferred Stock - Redemption Value.

- L, useful life of capital goods: by two-digit industry, the useful life of capital goods is calculated as $L_{j} \equiv \frac{1}{N_{j}} \sum_{i \in j} \frac{P P E_{i, t-1}+D E P R_{i, t-1}+I_{i, t}}{D E P R_{i, t}}$, where $N_{j}$ is the number of firms, $i$, in industry $j$. Using the double-declining balance method, the implied depreciation rate for industry $j, \delta_{j}$, is $2 / L_{j}$.

- $K$, replacement value of capital stock: Using the method of Salinger and Summers (1983) the replacement value of the capital stock is constructed by firm from its book value using the recursion: $K_{i, t}=\left(K_{i, t-1} \frac{P_{K, t}}{P_{K, t-1}}+I_{i, t}\right)\left(1-\delta_{j}\right)$, where the recursion is initialized using the book value of capital.

- Tobin's $Q$ : $\left.\left[(\text { market value of equity })_{t-1}+(\text { debt })_{t-1} \text { - (inventories }\right)_{t-1}\right] / K_{t}$. 


\subsection{Sample Selection}

Starting from the dataset cstsann in the CRSP/Compustat Merged database, the following filters were applied:

- If the firm was involved in a merger or acquisition, then delete (using aftnt35: ='01' as indication of a Merger \& Acquisition)

- end-of-period capital (data 187) is not missing

- investment (data 30) is not missing

- operating profit (data 178) is not missing

- incorrect capital accumulation (only for data before 1994, due to data184 and data185 not being reported after 1997)

- if disinvestment $>$ end-of-period capital then delete

- if operating loss is greater than end-of-period capital then delete

- if operating profit is greater than 2.5 times end-of-period capital then delete

- if $\mathrm{q}$ is missing or $\mathrm{q}<0$ then delete

- if investment $($ data 30$)<0$ then delete

- if dis-investment (data107) $<0$ then delete 


\subsection{Solution Method}

To solve the firm's problem we first write it in terms of detrended variables: $k=$ $K / X, h=H / X, i=I / X$, and $i^{h}=I^{h} / X$. The value function is homogeneous of degree one in $K, H, I_{-1}$, and $X$. This property follows from the fact that we can write the value function as a sum of functions that are homogeneous of degree one in these four variables. The homogeneity property allows us to rewrite the problem of the firm as:

$$
v^{*}\left(k, h, i_{-1}, z\right)=\max _{i, k^{\prime}, h^{\prime}}\left[z k^{\alpha} h^{\omega}-\theta-i-i^{h}+\beta \gamma \int v^{*}\left(k^{\prime}, h^{\prime}, i, z^{\prime}\right) F\left(d z^{\prime}, z\right)\right],
$$

subject to:

$$
\begin{gathered}
\gamma k^{\prime}=i\left[1-\xi\left(\gamma i / i_{-1}-\gamma\right)^{2}\right]+(1-\delta) k . \\
\gamma h^{\prime}=i^{h}+(1-\delta) h .
\end{gathered}
$$

To reduce the dimension of the state space we optimize out $h^{\prime}$ and use the fact that $h$ matters for the value of the firm but not for choosing the optimal level of $h^{\prime}$. The resulting firm problem is:

$$
v\left(k, i_{-1}, z\right)=\max _{i, k^{\prime}}\left[A z^{1 /(1-\alpha)} k^{\omega /(1-\alpha)}-\theta-i+\beta \gamma \int v\left(k^{\prime}, i, z^{\prime}\right) F\left(d z^{\prime}, z\right)\right],
$$

subject to the constraint (6.1). The constant $A$ is given by:

$$
A=\left[\frac{\alpha}{1-\beta(1-\delta)}\right]^{\alpha /(1-\alpha)}\left[1-\frac{\alpha}{1-\beta(1-\delta)}\right]
$$

The original value function is given by:

$$
v^{*}\left(k, h, i_{-1}, z\right)=v\left(k, i_{-1}, z\right)+(1-\delta) h .
$$

We obtain numerical solutions to the model with CEE adjustment costs using the following algorithm developed in Lkhagvasuren (2006): 
1. Define a coarse grid for $\left(k, i_{-1}, z\right)$;

2. Choose a guess for $v\left(k, i_{-1}, z\right)$ and evaluate it on the coarse grid;

3. Choose a fine grid for $i_{-1}$;

4. Generate a fine grid for $k$ compatible with fine grid for $i_{-1}$ using the resource constraint, (6.1);

5. Use bilinear interpolation to evaluate $v\left(k, i_{-1}, z\right)$ for every value of $z$ on the fine grid for $i_{-1}$ and $z ;^{14}$

6 . Find the optimal value of $i$ for every $\left(k, i_{-1}, z\right)$ combination;

7. Save the new value of $v\left(k, i_{-1}, z\right)$ evaluated on the coarse grid;

8. Save the policy function for $i, i\left(k, i_{-1}, z\right)$, evaluated on the fine grid;

9. Check whether the value function has converged;

10. If the value function has converged then stop; else go to step 5;

To simulate the model we can use a bilinear interpolation of $i\left(k, i_{-1}, z\right)$ evaluated for every $z$, for every pair $\left(k, i_{-1}\right)$ evaluated on the fine grid. This interpolation procedure avoids $k$ and $i_{-1}$ having to take values on the real line.

\footnotetext{
${ }^{14}$ Bilinear interpolation is an extension of linear interpolation for bivariate functions. Suppose we know the values of the function $f(x, y)$ evaluated at four points: $\left(x_{1}, y_{1}\right),\left(x_{2}, y_{1}\right),\left(x_{1}, y_{2}\right)$, and $\left(x_{2}, y_{2}\right)$. Then $f(x, y) \simeq \frac{f\left(x_{1}, y_{1}\right)}{\left(x_{2}-x_{1}\right)\left(y_{2}-y_{1}\right)}\left(x_{2}-x\right)\left(y_{2}-y\right)+\frac{f\left(x_{2}, y_{1}\right)}{\left(x_{2}-x_{1}\right)\left(y_{2}-y_{1}\right)}\left(x-x_{1}\right)\left(y_{2}-y\right)+$ $\frac{f\left(x_{1}, y_{2}\right)}{\left(x_{2}-x_{1}\right)\left(y_{2}-y_{1}\right)}\left(x_{2}-x\right)\left(y-y_{1}\right)+\frac{f\left(x_{2}, y_{2}\right)}{\left(x_{2}-x_{1}\right)\left(y_{2}-y_{1}\right)}\left(x-x_{1}\right)\left(y-y_{1}\right)$.
} 


\subsection{Estimation Method}

The objective of the simulated method of moments is to find the parameter vector $\hat{\Phi}$ that minimizes the distance between empirical $\left(\Psi_{D}\right)$ and simulated moments $(\Psi(\Phi))$ :

$$
L(\hat{\Phi})=\min \left[\Psi(\Phi)-\Psi_{D}\right]^{\prime} W\left[\Psi(\Phi)-\Psi_{D}\right]
$$

The weighting matrix, $W$, is obtained using the variance-covariance matrix of the empirical moments, $\Omega_{D}$ :

$$
W=\frac{1}{\Omega_{D}(1+1 / k)},
$$

where $k=$ length of simulation/length of sample. We estimate the matrix $\Omega_{D}$ using a block-bootstrap method as follows. We form $m$ samples. Each sample consists of data for $n$ firms drawn with replacement from our data set. For each of the $m$ samples we compute the vector of empirical moments. We use the $m$ observations on the vector of moments to estimate the variance-covariance matrix of the empirical moments, $\Omega_{D}$.

We solve the minimization problem (6.2) using an annealing algorithm. The first step consists in choosing initial values for the parameter vector, $\Phi$, admissible ranges for the parameters, as well as the "temperature" and the step size. As we discuss below, the temperature controls the probability that, given the best parameter vector so far, $\Phi^{*}$, we accept a parameter vector $\Phi^{\prime}$ that yields a worse fit $\left(L\left(\Phi^{\prime}\right)>L\left(\Phi^{*}\right)\right)$. This procedure is used to avoid convergence to a local minimum. We start with a high temperature value, so that the algorithm explores different regions of the parameter space.

The second step is to generate a new parameter vector, $\Phi^{\prime}$, by adding random shocks to the elements of $\Phi^{*}$ within their admissible range. Next we solve the model using value-function iteration for the parameter vector $\Phi^{\prime}$ and simulate 1940 representative firms (each with 23 years of data). Since the number of firms 
in our Compustat sample is equal to 194, this implies that $k$ in (6.3) equals 10. The fourth step consists in computing the simulated moments and $L\left(\Phi^{\prime}\right)$. If $L\left(\Phi^{\prime}\right)<L\left(\Phi^{*}\right)$ we set $\Phi^{*}=\Phi^{\prime}$. If $L\left(\Phi^{\prime}\right)>L\left(\Phi^{*}\right)$ we set $\Phi^{*}=\Phi^{\prime}$ with probability $\exp \left[-\left(L\left(\Phi^{\prime}\right)-L\left(\Phi^{*}\right)\right) /\right.$ temperature $]$. Finally, we reduce the values of temperature and step size before going back to step two. The vector of parameter estimates is the one that generates the lowest value of $L$. We denote this vector by $\hat{\Phi}$.

To verify the convergence properties of our estimation procedure, we used a simple robustness check. Starting with a parameter vector $\tilde{\Phi}$, we simulate a panel of firms and compute the simulated moments, $\Psi(\tilde{\Phi})$. We then use the SMM procedure described above to fit these moments. Ideally, we would like the parameter estimates $\hat{\Phi}$ to be as close as possible to the true parameter values $\tilde{\Phi}$ (the ones that generated the data). Failure to do so may indicate that the estimation procedure is not adequate or that the model parameters are not identified. We find that our procedure can recover reasonably well the true parameter values. This result is also confirmed by the fact that we obtain similar parameter estimates across SMM runs with different starting values. 
Table 1: Summary statistics, data and model implications

\begin{tabular}{|c|c|c|c|c|c|c|}
\hline & \multicolumn{3}{|c|}{$\begin{array}{l}\text { Median across large firms (4th } \\
\text { quartile of Compustat firms)* }\end{array}$} & \multicolumn{3}{|c|}{$\begin{array}{c}\text { CEE model } \\
\text { Regimes }\end{array}$} \\
\hline & $1981-2003$ & 1981-1992 & $1993-2003$ & All & Low & High \\
\hline $\begin{array}{l}\text { Time-series } \\
\text { average }\end{array}$ & & & & & & \\
\hline$Q$ & $\begin{array}{l}1.298 \\
(0.106)\end{array}$ & $\begin{array}{l}0.950 \\
(0.035)\end{array}$ & $\begin{array}{l}1.892 \\
(0.164)\end{array}$ & 1.181 & 0.926 & 1.440 \\
\hline $1 / K$ & $\begin{array}{l}0.150 \\
(0.011)\end{array}$ & $\begin{array}{l}0.146 \\
(0.012)\end{array}$ & $\begin{array}{l}0.161 \\
(0.008)\end{array}$ & 0.152 & 0.131 & 0.174 \\
\hline Cash Flow/K & $\begin{array}{l}0.169 \\
(0.014)\end{array}$ & $\begin{array}{l}0.155 \\
(0.014)\end{array}$ & $\begin{array}{l}0.199 \\
(0.017)\end{array}$ & 0.170 & 0.157 & 0.184 \\
\hline $\begin{array}{l}\text { Time-series } \\
\text { standard } \\
\text { deviations }\end{array}$ & & & & & & \\
\hline$Q$ & $\begin{array}{l}0.625 \\
(0.083)\end{array}$ & $\begin{array}{l}0.256 \\
(0.023)\end{array}$ & $\begin{array}{l}0.589 \\
(0.081)\end{array}$ & 0.309 & 0.134 & 0.201 \\
\hline $1 / K$ & $\begin{array}{l}0.055 \\
(0.003)\end{array}$ & $\begin{array}{l}0.050 \\
(0.003)\end{array}$ & $\begin{array}{l}0.046 \\
(0.003)\end{array}$ & 0.054 & 0.042 & 0.056 \\
\hline Cash Flow/K & $\begin{array}{l}0.078 \\
(0.007)\end{array}$ & $\begin{array}{l}0.046 \\
(0.005)\end{array}$ & $\begin{array}{l}0.089 \\
(0.009)\end{array}$ & 0.072 & 0.047 & 0.089 \\
\hline Skewness & & & & & & \\
\hline$Q$ & $\begin{array}{l}0.577 \\
(0.071)\end{array}$ & $\begin{array}{l}0.160 \\
(0.067)\end{array}$ & $\begin{array}{l}0.350 \\
(0.069)\end{array}$ & 0.362 & & \\
\hline $1 / K$ & $\begin{array}{l}0.418 \\
(0.060)\end{array}$ & $\begin{array}{l}0.320 \\
(0.058)\end{array}$ & $\begin{array}{l}0.330 \\
(0.050)\end{array}$ & 0.328 & & \\
\hline Cash Flow/K & $\begin{array}{l}0.245 \\
(0.054)\end{array}$ & $\begin{array}{l}-0.040 \\
(0.062)\end{array}$ & $\begin{array}{l}0.050 \\
(0.066)\end{array}$ & 0.339 & & \\
\hline $\begin{array}{l}\text { Serial } \\
\text { correlation }\end{array}$ & & & & & & \\
\hline$Q$ & $\begin{array}{l}0.838 \\
(0.012)\end{array}$ & & & 0.834 & & \\
\hline $1 / K$ & $\begin{array}{l}0.600 \\
(0.021)\end{array}$ & & & 0.566 & & \\
\hline Cash Flow/K & $\begin{array}{l}0.540 \\
(0.034)\end{array}$ & & & 0.497 & & \\
\hline
\end{tabular}

Bootstrap standard errors are in parentheses.

*For each variable, we compute the time series average for each firm in the sample, and repc " $Q$ " is Tobin's $Q, I$ is investment in property, plant, and equipment, and $K$ is the capital stock. Construction of the variables is described in the text and in the data appendix. 


\section{Table 2: Data and model regressions}

Dependent variable $\mathrm{I} / \mathrm{K}$, standard errors in parenthesis

Panel A : Pooled OLS

\begin{tabular}{l||ccccc} 
Regressors & 1 & 2 & 3 & 4 & 5 \\
\hline \hline Data & & & & & \\
& & & & & \\
Constant & 0.1406 & 0.2796 & 0.0413 & 0.2190 & 0.0849 \\
& $(0.0016)$ & $(0.0032)$ & $(0.0023)$ & $(0.0052)$ & $(0.005)$ \\
$(\mathrm{I} / \mathrm{K})_{\mathrm{t}-1}$ & & & 0.7515 & & 0.6253 \\
& & & $(0.0116)$ & & $(0.0132)$ \\
$\ln \left(\mathrm{Q}_{\mathrm{t}}\right)$ & 0.0600 & & & 0.0331 & 0.0126 \\
& $(0.0016)$ & & & $(0.0023)$ & $(0.0019)$ \\
$\ln (\text { Cash Flow } / \mathrm{K})_{\mathrm{t}}$ & & 0.0651 & & 0.0387 & 0.017 \\
& & $(0.0020)$ & & $0.0024)$ & $(0.0020)$ \\
\hline $\mathrm{R}^{2}$ & 0.29 & 0.30 & 0.57 & 0.34 & 0.61
\end{tabular}

Panel B : Panel regressions with firm fixed effects

\begin{tabular}{l||ccccc} 
Regressors & 1 & 2 & 3 & 4 & 5 \\
\hline \hline Data & & & & & \\
\multirow{2}{*}{ Constant } & 0.1532 & 0.1990 & 0.0875 & 0.1589 & 0.0931 \\
& $(0.0019)$ & $(0.0064)$ & $(0.0060)$ & 0.0073 & $(0.0071)$ \\
$(\mathrm{I} / \mathrm{K})_{\mathrm{t}-1}$ & & & 0.4820 & & 0.4462 \\
& & & $(0.0352)$ & & $(0.0355)$ \\
$\ln \left(\mathrm{Q}_{\mathrm{t}}\right)$ & 0.0336 & & & 0.0316 & 0.0208 \\
& $(0.0040)$ & & & $(0.0041)$ & $(0.0034)$ \\
$\ln (\text { Cash Flow/K })_{\mathrm{t}}$ & & 0.0173 & & 0.0026 & 0.0061 \\
& & $(0.0038)$ & & $(0.0038)$ & $(0.0029)$ \\
\hline $\mathrm{R}^{2}$ & 0.29 & 0.30 & 0.57 & 0.30 & 0.60
\end{tabular}

Panel C : Dynamic Arellano-Bond panel regressions with firm fixed effects and robustness checks

\begin{tabular}{l||ccccc} 
Regressors & 1 & 2 & 3 & 4 & 5 \\
\hline \hline Data & & & & & \\
& & & & & \\
Constant & 0.0894 & $\mathbf{0 . 0 7 4 9}$ & 0.0961 & 0.0889 & 0.0633 \\
& $(0.0053)$ & $\mathbf{( 0 . 0 0 8 0 )}$ & $(0.0096)$ & $(0.0150)$ & $(0.0091)$ \\
$(\mathrm{I} / \mathrm{K})_{\mathrm{t}-1}$ & 0.4707 & $\mathbf{0 . 4 1 8 7}$ & 0.3785 & 0.3086 & 0.4192 \\
& $(0.0301)$ & $\mathbf{( 0 . 0 3 1 1 )}$ & $(0.0284)$ & $(0.0621)$ & $(0.0351)$ \\
$\ln \left(\mathrm{Q}_{\mathrm{t}}\right)$ & & $\mathbf{0 . 0 4 0 5}$ & 0.0624 & 0.0556 & 0.0430 \\
& & $\mathbf{( 0 . 0 0 4 9 )}$ & $(0.0063)$ & $(0.0091)$ & $(0.0059)$ \\
$\ln ($ Cash Flow/K) $\mathrm{t}$ & & $\mathbf{- 0 . 0 0 1 4}$ & -0.0017 & -0.0093 & 0.0011 \\
& & $\mathbf{( 0 . 0 0 3 3 )}$ & $(0.0032)$ & $(0.0063)$ & $(0.0035)$ \\
\hline Year dummies & No & $\mathbf{N o}$ & Yes & No & No \\
Sample & $1981-2003$ & $\mathbf{1 9 8 1 - 2 0 0 3}$ & $1981-2003$ & $1981-1992$ & $1993-2003$
\end{tabular}

Panel D: Model regressions, regime switching

\begin{tabular}{l||ccccc} 
Regressors & 1 & 2 & 3 & 4 & 5 \\
\hline \hline CEE model & & & & & \\
& & & & & \\
Constant & $(0.1384$ & 0.2390 & 0.0662 & 0.1869 & $\mathbf{0 . 1 2 1 9}$ \\
& & $(0.0010)$ & $(0.0007)$ & $(0.0011)$ & $\mathbf{( 0 . 0 0 1 1 )}$ \\
$(\mathrm{I} / \mathrm{K})_{\mathrm{t}-1}$ & & & 0.5650 & & $\mathbf{0 . 4 2 0 6}$ \\
& & & $(0.0041)$ & & $\mathbf{( 0 . 0 0 4 0 )}$ \\
$\ln \left(\mathrm{Q}_{\mathrm{t}}\right)$ & 0.1050 & & & 0.0836 & $\mathbf{0 . 0 5 3 0}$ \\
& $(0.0009)$ & & & $(0.0010)$ & $\mathbf{( 0 . 0 0 0 9 )}$ \\
$\ln (\text { Cash Flow } / \mathrm{K})_{\mathrm{t}}$ & & 0.0470 & & 0.0244 & $\mathbf{0 . 0 2 1 7}$ \\
& & $(0.0005)$ & & $(0.0005)$ & $\mathbf{( 0 . 0 0 0 5 )}$ \\
\hline $\mathrm{R}^{2}$ & 0.27 & 0.17 & 0.32 & 0.30 & $\mathbf{0 . 4 5}$
\end{tabular}




\section{Table 3: Parameter estimates}

\begin{tabular}{|c|c|}
\hline & Regime switching \\
\hline $\begin{array}{l}\text { Estimated parameters } \\
\text { Adjustment cost : } \xi \\
\text { Adjustment cost : } v\end{array}$ & $\begin{array}{c}0.929 \\
(0.0113)\end{array}$ \\
\hline Fixed cost: $\phi$ & $\begin{array}{c}86.22 \\
(1.2539)\end{array}$ \\
\hline Discount factor: $\beta$ & $\begin{array}{c}0.9484 \\
(0.0004)\end{array}$ \\
\hline Shock range: $\sigma$ & $\begin{array}{l}0.0915 \\
0.0008\end{array}$ \\
\hline $\begin{array}{l}\text { Low regime center shock: } \mu \mathrm{L} \\
\text { High regime center shock: } \mu \mathrm{H}\end{array}$ & \\
\hline Low regime shock range: $\sigma \mathrm{L}$ & $\begin{array}{c}0.274 \\
(0.0017)\end{array}$ \\
\hline High regime shock range: $\sigma \mathrm{H}$ & $\begin{array}{c}0.5875 \\
(0.0038)\end{array}$ \\
\hline Switching parameter 1 & $\begin{array}{c}0.0323 \\
(0.0013)\end{array}$ \\
\hline Switching parameter 2 & $\begin{array}{c}0.0744 \\
(0.0019)\end{array}$ \\
\hline Shock persistence: $\rho$ & $\begin{array}{c}0.5595 \\
(0.0029)\end{array}$ \\
\hline Weight on flexible capital: $\omega$ & $\begin{array}{c}0.0701 \\
(0.0005)\end{array}$ \\
\hline Calibrated parameters & \\
\hline Mean shock: $\mu$ & 1.00 \\
\hline Returns to scale: $\alpha+\omega$ & 0.80 \\
\hline Depreciation rate: $\delta$ & 0.12 \\
\hline Growth: y & 1.03 \\
\hline
\end{tabular}

Standard errors in parenthesis 


\section{Table 4: Estimated Markov chain}

Support of the distribution

\begin{tabular}{cccccc}
\multicolumn{3}{c}{ Low Regime } & \multicolumn{3}{c}{ High Regime } \\
$\mu^{\mathrm{L}}-\sigma^{\mathrm{L}}$ & $\mu^{\mathrm{L}}$ & $\mu^{\mathrm{L}}+\sigma^{\mathrm{L}}$ & $\mu^{\mathrm{H}}-\sigma^{\mathrm{H}}$ & $\mu^{\mathrm{H}}$ & $\mu^{\mathrm{H}}+\sigma^{\mathrm{H}}$ \\
\hline 0.7296 & 1.0447 & 1.3598 & 0.5795 & 1.2550 & 1.9305
\end{tabular}

Transition matrix

\begin{tabular}{c|cccccc|}
\multicolumn{1}{c}{} & $\mu^{\mathrm{L}}-\sigma^{\mathrm{L}}$ & $\mu^{\mathrm{L}}$ & $\mu^{\mathrm{L}}+\sigma^{\mathrm{L}}$ & $\mu^{\mathrm{H}}-\sigma^{\mathrm{H}}$ & $\mu^{\mathrm{H}}$ & $\mu^{\mathrm{H}}+\sigma^{\mathrm{H}}$ \\
\cline { 2 - 7 }$\mu^{\mathrm{L}}-\sigma^{\mathrm{L}}$ & 0.608 & 0.3435 & 0.0485 & 0 & 0 & 0 \\
$\mu^{\mathrm{L}}+\sigma^{\mathrm{L}}$ & 0.1662 & 0.6353 & 0.1662 & 0.0323 & 0 & 0 \\
$\mu^{\mathrm{H}}-\sigma^{\mathrm{H}}$ & 0.0449 & 0.3179 & 0.5627 & 0.0744 & 0 & 0 \\
$\mu^{\mathrm{H}}$ & 0 & 0 & 0.0744 & 0.5627 & 0.3179 & 0.0449 \\
$\mu^{\mathrm{H}}+\sigma^{\mathrm{H}}$ & 0 & 0 & 0.0323 & 0.1662 & 0.6353 & 0.1662 \\
\cline { 3 - 7 } & 0 & 0 & 0 & 0.0485 & 0.3435 & 0.608 \\
\hline
\end{tabular}


Figure 1 : Investment rate $(\mathrm{I} / \mathrm{K})_{\mathrm{t}}$ against $(\mathrm{I} / \mathrm{K})_{\mathrm{t}-1}, \mathrm{Q}_{\mathrm{t}}$ and $(\mathrm{CF} / \mathrm{K})_{\mathrm{t}}$

$\mathrm{I}(\mathrm{t}) / \mathrm{K}(\mathrm{t})$ and $\mathrm{I}(\mathrm{t}-1) / \mathrm{K}(\mathrm{t}-1)$

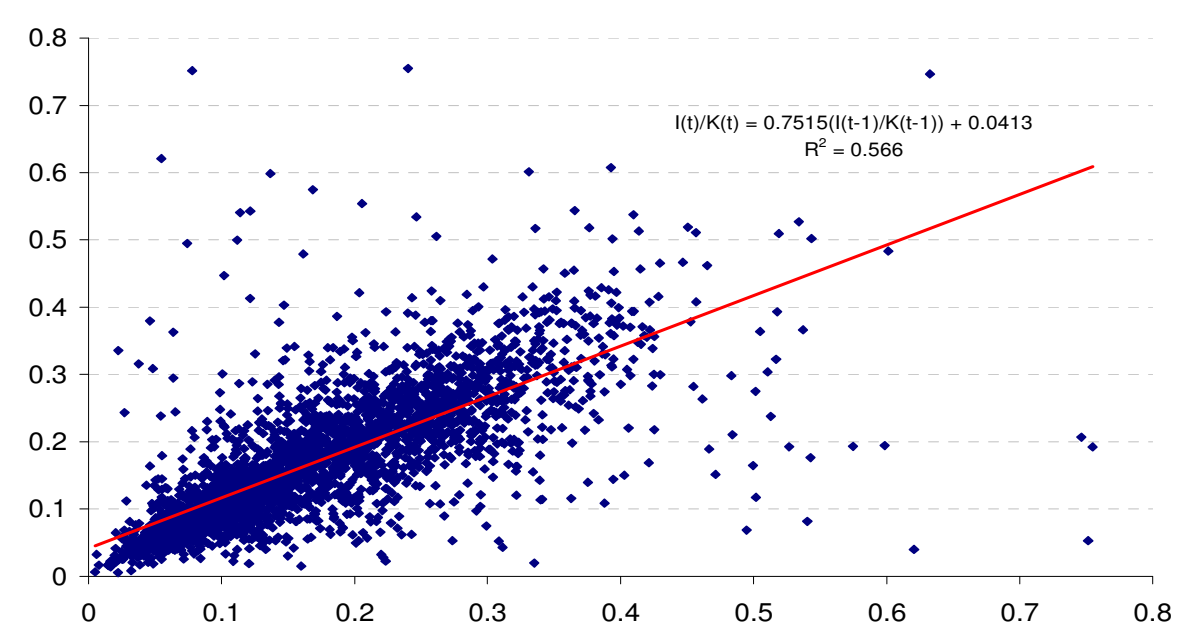

$\mathrm{I} / \mathrm{K}$ and $\mathrm{q}$

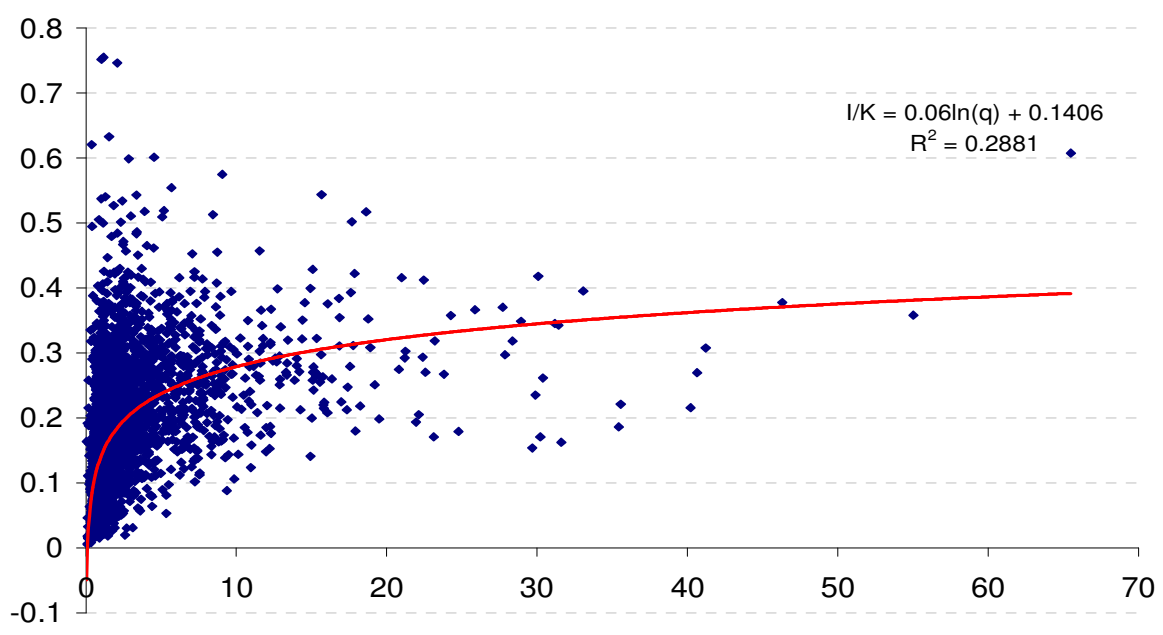

$\mathrm{I} / \mathrm{K}$ and $\mathrm{CF} / \mathrm{K}$

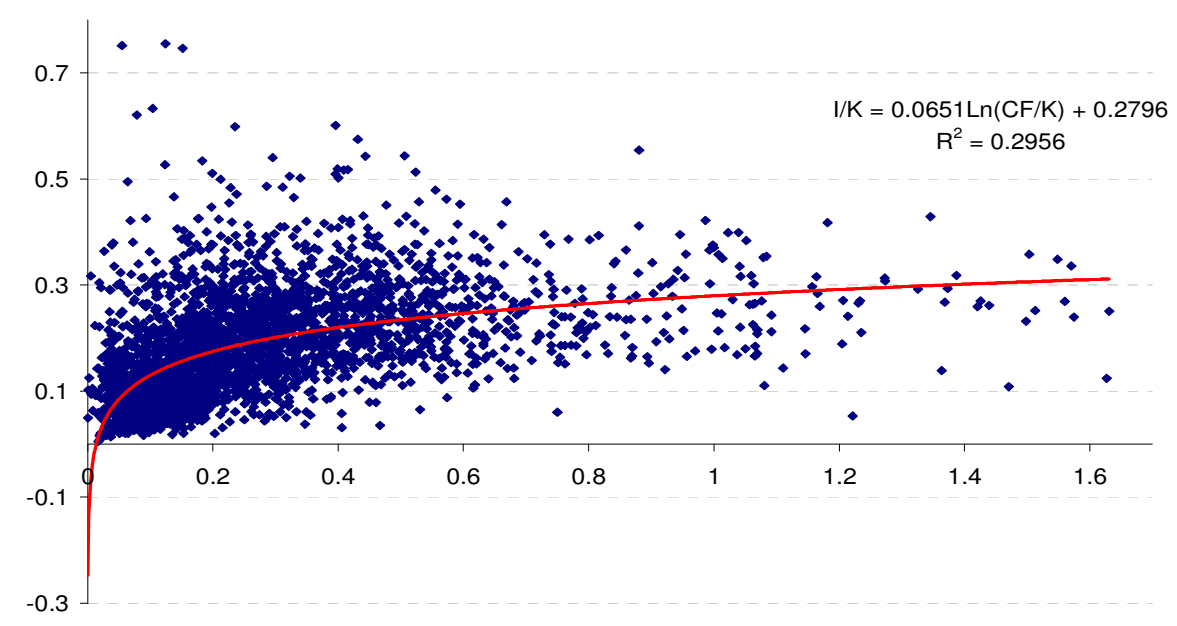

